\title{
Correction to: Power efficient uplink scheduling in SC-FDMA: benchmarking by column generation
}

\author{
Yixin Zhao ${ }^{1} \cdot$ Torbjörn Larsson $^{2} \cdot$ Di Yuan $^{3}$ - Elina Rönnberg ${ }^{2} \cdot$ Lei Lei $^{3}$
}

Published online: 2 July 2019

๑) Springer Science+Business Media, LLC, part of Springer Nature 2019

\section{Correction to: Optim Eng (2016) 17:695-725 \\ https://doi.org/10.1007/s11081-015-9304-z}

At the time of the final publication of the paper, in December 2016, Yixin Zhao's affiliation had changed. Her affiliation is School of Automation, Nanjing University of Science and Technology, 210094, China, since August 2016.

Publisher's Note Springer Nature remains neutral with regard to jurisdictional claims in published maps and institutional affiliations.

The original article can be found online at https://doi.org/10.1007/s11081-015-9304-z.

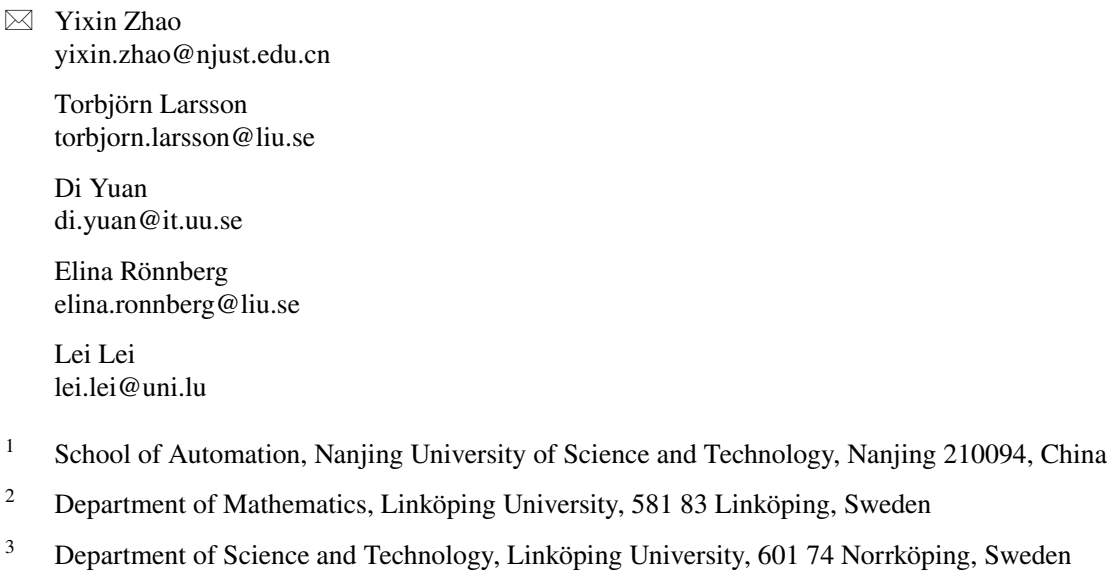

